\title{
Blemish Formation in Processed Microfilm II
}

\author{
C. I. Pope \\ Institute for Basic Standards, National Bureau of Standards, \\ Washington, D.C. 20234
}

(October 3, 1969)

\begin{abstract}
Gaseous peroxides form blemishes on some processed microfilms. Two procedures are given for testing the blemish susceptibility of processed microfilm, one using peroxide paper and the other zinc powder as a source of peroxide. The susceptibility of microfilm to blemish formation decreased when conditioned at 86 percent relative humidity and $26^{\circ} \mathrm{C}$. Coarse-grain microfilms are less susceptible to blemish formation than fine-grain microfilm. Fine-grain microfilms fixed in ammonium thiosulfate were less susceptible to blemish formation than those fixed in sodium thiosulfate. Oven-aged microfilm storage cartons were found to generate peroxide when wetted. The microfilm base readily absorbed hydrogen peroxide.
\end{abstract}

Key words: Archival record film, microfilm, microfilm storage cartons, permanent record film, peroxıdes, redox blemishes, zinc powder.

\section{Introduction}

A previous study [1 ${ }^{1}$ showed that blemishes were formed in processed microfilm by oxidizing and reducing agents, probably peroxides, emitted by paper cartons in which the microfilm was stored. Further study has led to the development of reproducible test procedures for determining the susceptibility of processed microfilm to such blemish formation. Other factors affecting the formation of blemishes were also investigated. In this paper the term "blemish" means the redox type of blemish.

\section{Test Procedures for Determining the Sus- ceptibility of Processed Microfilm to Blemish Formation}

Procedures were developed using peroxide paper and zinc powder as peroxide sources for testing the susceptibility of processed microfilm to blemish formation. The test apparatus, methods of maintaining relative humidities, and the solutions used to process the films in this study are described in a previous publication [1]. A fine grain microfilm sample which is known to be susceptible to blemish formation should be used as a control with a microfilm sample being tested for blemish formation.

${ }^{1}$ Figures in brackets indicate the literature references at the end of this paper.

\subsection{Peroxide Paper Test}

\section{a. Procedure for Making the Peroxide Paper}

Whatman No. 3 MM filter paper ${ }^{2}$ which is used in chromatography, was selected for this test method. The filter paper was immersed $30 \mathrm{~min}$ in a 5 -percent solution of hydrogen peroxide at room temperature, with occasional stirring, and hung in a ventilating hood to dry. Eight samples of the paper, $5 \mathrm{~cm}$ by $10 \mathrm{~cm}$, were used in each run. The hydrogen peroxide concentration in the filter paper was determined after drying $2 \mathrm{hr}$ and at the end of each $30 \mathrm{~min}$ interval thereafter during the drying time. The hydrogen peroxide concentration was immediately plotted against the drying time and, by extrapolating the curve, it was possible to estimate when to terminate the drying to obtain a concentration of approximately $85 \mu \mathrm{g} / \mathrm{cm}^{2}$. If the concentration is not over $150 \mu \mathrm{g} / \mathrm{cm}^{2}$, the paper is usable since the area may be adjusted in the film test. After drying, the peroxide paper was immediately stored in a sealed glass bottle containing anhydrous calcium sulfate, in a refrigerator at $-10{ }^{\circ} \mathrm{C}$. Portions of the paper used in testing for blemish formation were removed rapidly and the bottle was immediately returned to the refrigerator. During storage, the concentration of hydrogen peroxide in the filter paper decreased a few percent after 30 days, about 20 percent after 100 days, and about 30 percent after 6 months.

\footnotetext{
${ }^{2} \mathrm{~A}$ commercial material is identified in this paper in order to adequately specify the experimental procedure. Such identification does not imply recommendation or endorse ment by the National Bureau of Standards.
} 


\section{b. Peroxide Content of the Peroxide Paper}

The procedure for measuring the residual hydrogen peroxide in the peroxide paper was as follows. A sample of the paper, $2 \mathrm{~cm}$ by $4 \mathrm{~cm}$, was immersed in $30 \mathrm{ml}$ of distilled water for $15 \mathrm{~min}$, after which it was removed and washed with about $15 \mathrm{ml}$ of distilled water. About $5 \mathrm{ml}$ of 1-percent starch solution, 3 drops of a 3-percent ammonium molybdate solution, $20 \mathrm{ml} 4 N$ sulfuric acid solution and $1 \mathrm{~g}$ of potassium iodide were added to the above solution and the iodine liberated by the peroxide titrated with $0.01 N$ sodium thiosulfate. The hydrogen peroxide content of $1 \mathrm{~cm}^{2}$ of the paper was calculated from the amount of sodium thiosulfate required.

A study was made to determine the effect of the concentration of the residual hydrogen peroxide in the peroxide paper used in the test for blemish formation in microfilm. The optimum concentration of residual hydrogen peroxide was found to be about 85 $\mu \mathrm{g} / \mathrm{cm}^{2}$. The microfilm samples were exposed in the desiccator to the peroxide paper for $24 \mathrm{hr}$ at 86 percent relative humidity (maintained by a saturated solution of potassium chloride) and $26{ }^{\circ} \mathrm{C}$. Three or four consecutive exposures of the microfilm to a fresh $1 \mathrm{~cm}^{2}$ piece of paper containing about $85 \mu \mathrm{g}$ of hydrogen peroxide were usually sufficient to develop well defined spots. The three or four exposures to $1 \mathrm{~cm}^{2}$ of the paper developed spots more like the natural type than one exposure to a 3 or $4 \mathrm{~cm}^{2}$ piece.

The first exposure formed very small white spots and occasionally a few small light yellow spots. With further exposures the spots began to enlarge, became more yellow and formed a ring structure. Most of the spots appeared to start with the first exposure. When the microfilm sample was desiccated over anhydrous calcium sulfate $24 \mathrm{hr}$ at room temperature between each exposure to peroxide paper the spots developed a sharper ring structure, resembling more closely the natural spots. A $\frac{1}{2} \mathrm{~cm}^{2}$ piece of paper containing approximately $85 \mu \mathrm{g}$ of hydrogen peroxide was just about as effective as $1 \mathrm{~cm}^{2}$ having $85 \mu \mathrm{g}$, but when the concentration was about $40 \mu \mathrm{g} / \mathrm{cm}^{2}, 2 \mathrm{~cm}^{2}$ did not cause as much spot development as $1 \mathrm{~cm}^{2}$ containing $85 \mu \mathrm{g}$. One exposure to $40 \mu \mathrm{g}$ of hydrogen peroxide caused development of a few minute white spots in the high densities of the microfilm samples. The paper emitted about 80 percent of its peroxide during the first $4 \mathrm{hr}$ of the test, when it initially contained about $85 \mu \mathrm{g} / \mathrm{cm}^{2}$.

The test procedure was used on old rolls of microfilm processed several years ago and having spots on the leader and in the information near the leader. Samples from some of the rolls in blemish-free areas developed spots after one or two exposures to $1 \mathrm{~cm}^{2}$ of paper at optimum concentration while samples from other rolls developed no spots.

\subsection{Zinc Powder Test}

Henn and Wiest [2] have shown that film may be tested for blemish formation by incubating the film in contact with zinc powder. Tests showed that zinc powder placed some distance from the microfilm sample generated sufficient peroxide to form spots in microfilm susceptible to blemish formation. The apparatus used in this test was the same as that described in the above paper peroxide test. A layer of zinc powder about 2 to $3 \mathrm{~mm}$ thick was placed in the glass dish which supported the peroxide paper.

Microfilm susceptible to blemish formation readily developed spots and image-edge attack after exposure to the zinc powder at 76 percent relative humidity (maintained by saturated sodium chloride) for 15 days at $26{ }^{\circ} \mathrm{C}$. The spots began to form after 3 to 5 days exposure. The spots were more numerous than in the paper test and were light yellow in color as compared to the deeper yellow in the paper test. Tests were made on microfilms with varying degrees of spot susceptibility and the zinc test correlated well with the paper test. Microfilms that did not form spots with the paper test formed no spots with the zinc test. These results show that the zinc test may be used to determine the blemish susceptibility of processed microfilm, though the paper test forms spots more like the natural ones in color and appearance.

Microfilms exposed to the zinc powder at 76 percent relative humidity for 5 days at $40{ }^{\circ} \mathrm{C}$ developed spots very similar, in number and color, to those formed in the paper test. The test was not satisfactory when conducted at 76 percent relative humidity and $50{ }^{\circ} \mathrm{C}$.

\subsection{Processing the Control Microfilm Sample for Testing Blemishes in Microfilm}

Microfilm susceptible to blemish formation should be used as a control in testing microfilm for blemish formation. The test for blemish susceptibility in a processed microfilm sample was the comparison of its blemish formation, if any, with that of the control sample. It has been shown [1] that fine-grain microfilm washed in chlorine-free tap water during processing formed spots readily when exposed to peroxide. About $50-\mathrm{cm}$ lengths of a fine-grain microfilm were exposed to an image-pattern, developed, stopped, fixed in the acid hardening fixing bath and washed in 1-liter baths of chlorine-free tap water [1] in 1.5-liter beakers for $30 \mathrm{~min}$. Eight baths were used, $2 \mathrm{~min}$ in the first two, $3 \mathrm{~min}$ in the next two, and $5 \mathrm{~min}$ in the remaining baths. The sample was transferred from beaker to beaker and agitated with a glass rod. The temperature of the processing solutions and wash water was $26^{\circ} \mathrm{C}$. The sample was dried $24 \mathrm{hr}$ at room temperature and humidity and stored in a metal can about a week before exposing to peroxide. Microfilm washed in chlorine-free tap water from four sources suffered heavy spot formation. Microfilm washed in distilled water and in water from one well formed no spots. Microfilm washed in water drawn from the hot tap and cooled to room temperature formed none or only a few spots. The distilled water, well water, and hot tap water contained no residual chlorine. The effect of the type of wash water may be due to its influence on the residual thiosulfate concentration. Samples washed in chlorine-free tap water contained 0.0 to $0.6 \mu \mathrm{g} / \mathrm{cm}^{2}$ of residual sodium thiosulfate for the image area while samples washed in the other wash 
waters generally had a hicher concentration. If the residual sodium thiosulfate in the microfilm was not reduced below $1 \mu \mathrm{g} / \mathrm{cm}^{2}$ by the chlorine-free tap water wash, spots did not form.

\section{Effect of Humidification on Blemish Forma- tion in Fine-Grain Microfilm}

The relative humidity was found to be a critical factor in testing processed microfilm for blemish formation. Tests were made with the peroxide paper on microfilms susceptible to blemish formation at 76,86 , and 97 percent relative humidity and $26{ }^{\circ} \mathrm{C}$. Only minute spots and even yellowing occured at 76 percent relative humidity. Spots and edge attack similar to the natural types formed at 86 percent relative humidity. At 97 percent relative humidity (maintained with saturated potassium sulfate) no spots formed but a slight reddish even attack sometimes took place. The 76 percent relative humidity was too dry and the 97 percent relative humidity was too wet to form naturallooking spots. Natural-type spots formed in the zinc powder test at 76 percent relative humidity. Zinc powder at 86 percent relative humidity caused only even yellowing.

A study was made to determine the effect of conditioning processed fine-grain microfilm at 86 percent relative humidity and $26^{\circ} \mathrm{C}$ before testing. The microfilm samples tested were highly susceptible to blemish formation when they had been conditioned after processing in metal cans at room humidity, which ranged between about 25 and 50 percent, and room temperature, which was $26^{\circ} \mathrm{C}$. In these tests a control sample stored at room humidity was exposed to the peroxide paper along with a sample which had been conditioned at 86 percent relative humidity. Numerous spots always formed on the control samples in the low and high silver density areas. The test samples were conditioned at 86 percent relative humidity and $26^{\circ} \mathrm{C}$ (over a saturated solution of potassium chloride) in a desiccator jar on a porcelain plate with the emulsion side up, removed, stored at room humidity and exposed to the peroxide paper. The results of tests for four different conditioning periods at 86 percent relative humidity and briefer periods in room air are given in table 1 . Blemish susceptibility was reduced to about 50 percent after conditioning at 86 percent relative humidity and $26^{\circ} \mathrm{C}$ for 14 days, to about 10 percent after 41 days, and to almost nothing after 7 months. The reduction of spot susceptibility by aging at this high humidity was probably caused by formation of silver chloride on the image silver. Residual chloride ions, which are always present in the gelatin layer of the processed microfilm, probably reacted readily with the image silver in the moist gelatin to form silver chloride, which would inhibit spot formation if present in excessive amounts. Microfilm samples conditioned at 81 percent relative humidity at $50^{\circ} \mathrm{C}$ for 1 day showed inhibition of spot formation comparable to conditioning the microfilm at 86 percent relative humidity and $26^{\circ} \mathrm{C}$ for 41 days. No spots formed on microfilm samples conditioned at 97 percent relative humidity and $26^{\circ} \mathrm{C}$ for 2 days.
TABLE 1. Effect of storage at 86 percent relative humidity and $26^{\circ} \mathrm{C}$ on blemish formation for one microfilm

\begin{tabular}{|c|c|}
\hline $\begin{array}{l}\text { Storage conditions for } \\
\text { microfilm samples before } \\
\text { exposure to peroxide }\end{array}$ & Observations \\
\hline $\begin{array}{l}7 \text { days at } 86 \text { percent relative } \\
\text { humidity, } 24 \mathrm{hr} \text { at room } \\
\text { humidity. }\end{array}$ & $\begin{array}{l}\text { The number of spots on the } \\
\text { samples was slightly less } \\
\text { than on the control samples. }\end{array}$ \\
\hline $\begin{array}{l}14 \text { days at } 86 \text { percent relative } \\
\text { humidity, } 24 \mathrm{hr} \text { at room } \\
\text { humidity. }\end{array}$ & $\begin{array}{l}\text { The number of spots on the } \\
\text { samples was about } 50 \text { percent } \\
\text { of those on the control samples } \\
\text { showing appreciable inhibition } \\
\text { of spot formation. Most of the } \\
\text { spots were in the high density } \\
\text { areas and were larger than } \\
\text { those on the control samples. }\end{array}$ \\
\hline $\begin{array}{l}41 \text { days at } 86 \text { percent relative } \\
\text { humidity, } 66 \text { days at room } \\
\text { humidity. }\end{array}$ & $\begin{array}{l}\text { The number of spots on the } \\
\text { samples was about } 10 \text { percent } \\
\text { of that on the control samples. } \\
\text { Spot formation was inhibited } \\
\text { more in the low density areas } \\
\text { than in the high and the edges } \\
\text { of the spots were not as well } \\
\text { defined as those in the control } \\
\text { samples. }\end{array}$ \\
\hline $\begin{array}{l}7 \text { months at } 86 \text { percent rela- } \\
\text { tive humidity, } 20 \text { days at } \\
\text { room humidity. }\end{array}$ & $\begin{array}{l}\text { A few spots formed in the high } \\
\text { density areas and none in the } \\
\text { low. The edges of the spots } \\
\text { were not as well defined as } \\
\text { those in the controls. }\end{array}$ \\
\hline
\end{tabular}

Tests were made to determine the effect of desiccation on blemish formation in processed microfilm. Microfilm strips were dried over anhydrous calcium sultate for 5 months at $26{ }^{\circ} \mathrm{C}$, stored 7 days at room humidity and $26^{\circ} \mathrm{C}$ and with control samples exposed to the peroxide paper. The number of spots formed in the low densities were appreciably less than on the control samples and slightly less in the high densities. The spots on the desiccated samples showed a better defined ring structure than those on the control samples. Other samples from the desiccated microfilm strips were exposed to peroxide paper after storage for about 6 months at room humidity and $26^{\circ} \mathrm{C}$. The spot formation was similar to that of the control samples. The tests showed that desiccation reduced the spot forming susceptibility but it recovered after storage for about 6 months at room humidity.

\section{Blemish Formation in Coarse-Grain Proc- essed Microfilm}

The tests described above in this and a previous paper [1] have been made on fine-grain microfilms. However, microfilms with a larger grain are also used for record purposes. This microfilm is designated as coarse-grain microfilm in this paper. A few blemishes, mostly spots, have been found in processed coarsegrain microfilms in actual storage. Observations made on all types of film in storage indicated that the susceptibility to blemish formation decreased as the grain size increased. The effect of processing variables was investigated for one coarse-grain microfilm. 
The coarse-grain 16-mm microfilm was exposed, developed, stopped, fixed, washed, dried, and exposed to peroxide by the same procedures as described for fine-grain microfilm [1]. Some microfilm samples were fixed in a neutral bath and others in an acid hardening bath, and samples were washed 3,15 , and $30 \mathrm{~min}$, respectively, at $26{ }^{\circ} \mathrm{C}$ in chlorine-free tap water. None of these samples formed spots on exposure to peroxide, although there was a light even yellowing of the silver image. Fine-grain microfilm was very susceptible to spot formation when processed by the same procedures. In another series of tests, mocrofilm samples were fixed in the nonhardening bath or the acid hardening bath and washed, $3,7 \frac{1}{2}, 15,30$, or $60 \mathrm{~min}$ in running tap water at $25{ }^{\circ} \mathrm{C}$, containing $1.2 \mathrm{ppm}$ of chlorine. There was a light even yellowing of the silver image for the 3 and $7 \frac{1}{2}$-min washes and a few spots without background yellowing for the 15, 30, and 60-min wash. Fine-grain microfilm processed by these same procedures formed many spots in samples washed $3 \mathrm{~min}$ but none in those washed 15, 30, and $60 \mathrm{~min}$. The tests suggest that chlorine in the tap wash water formed a trace of residual silver chloride in the image silver, making it susceptible to some spot formation in the longer washes. It is evident from these tests that grain size is one of the factors in blemish formation.

\section{Ammonium Thiosulfate Versus Sodium Thiosulfate for Fixing}

Tests were made to determine the effect of fixation in an acid hardening bath containing $200 \mathrm{~g}$ of anhydrous ammonium thiosulfate, $15 \mathrm{~g}$ of sodium sulfite, $15 \mathrm{ml}$ of glacial acetic acid, $7.5 \mathrm{~g}$ of boric acid, and $15 \mathrm{~g}$ of potassium aluminum sulfate per liter. A nonhardening bath, containing $150 \mathrm{~g}$ of anhydrous ammonium thiosulfate and $68 \mathrm{~g}$ of sodium bisulfite per liter, was also tried, as was a neutral bath containing $150 \mathrm{~g}$ of anhydrous ammonium thiosulfate per liter. A fine-grain 16-mm microfilm was exposed, developed, stopped, fixed, dried, and exposed to peroxide by the same procedure as previously described [1] except that ammonium thiosulfate fixing baths were used instead of the sodium thiosulfate baths.

Microfilm samples were fixed in the neutral bath and washed 3,15 , or $30 \mathrm{~min}$ in chlorine-free tap water at $26^{\circ} \mathrm{C}$. The samples formed large light yellow spots, light yellowing of the image silver and edge attack. The blemish attack was similar to that found on films fixed in neutral sodium thiosulfate.

Microfilm samples were fixed in the nonhardening bath and washed 3,15 , or $30 \mathrm{~min}$ in chlorine-free tap water at $26{ }^{\circ} \mathrm{C}$. The samples developed several small light yellow spots, some yellowing of the image silver, and slight edge attack. Resistance to spot formation was greater than in samples fixed in a nonhardening sodium thiosulfate bath.

Microfilm samples were fixed in the acid hardening bath and washed 3,15 , or $30 \mathrm{~min}$ in chlorine-free tap water at $26^{\circ} \mathrm{C}$. Samples washed 3 min developed a few small spots and a trace of even yellowing, but no attack on the edge of the information. No blemishes formed on samples washed 15 or 30 min. Thus microfilm fixed ' in an ammonium thiosulfate acid hardening bath was more resistant to blemish formation than that fixed in a sodium thiosulfate acid hardening bath. The same microfilm fixed in a sodium thiosulfate acid hardening bath and washed $30 \mathrm{~min}$ in chlorine-free tap water readily formed spots [1].

Microfilm samples were fixed in the acid hardening bath and washed $3,7 \frac{1}{2}, 15$, or $30 \mathrm{~min}$ in running tap water containing $1.2 \mathrm{ppm}$ of chlorine, at $25^{\circ} \mathrm{C}$. Samples washed 3 min showed a few spots with irregular edges and some even yellowing, but no attack on the edge of the image characters. No blemishes formed on samples washed $7 \frac{1}{2}, 15$, or $30 \mathrm{~min}$. The results in this last test approximate those obtained with films fixed in a sodium thiosulfate acid hardening bath and washed in tap water containing about $1 \mathrm{ppm}$ of chlorine.

Ammonium thiosulfate fixing made the microfilm more resistant to spot formation than sodium thiosulfate fixing, when the microfilm was washed in chlorine-free tap water. The susceptibility was about the same if the film was washed in tap water containing about 1 ppm of chlorine.

\section{Detection of Peroxide Evolved by Oven- Aged Storage Cartons}

Three paper cartons, made by three manufacturers and designed for storing 16-mm microfilm, were tested for peroxide formation due to aging. Tests for peroxide on the three cartons before aging were negative. The cartons were aged at $100 \pm 3^{\circ} \mathrm{C}$ in an oven without forced ventilation for 7 and 14 days or in a furnace oven at $175 \pm 5^{\circ} \mathrm{C}$ for $2 \mathrm{hr}$.

Hydrogen peroxide forms a soluble yellow complex compound with titanium in a sulfuric acid solution. When sulfuric acid is exposed to the gases emitted by aged paper, the acid takes on a yellowish tint. A deeper yellow color in the presence of titanium ions was taken as a positive test for the presence of peroxide.

The following procedure was used in making qualitative tests for peroxide evolved by the paper cartons. About $10 \mathrm{~g}$ of the paper carton stock was cut into $1 \mathrm{~cm}^{2}$ pieces and placed in a flat weighing bottle about $65 \mathrm{~mm}$ in diameter and $45 \mathrm{~mm}$ high, when closed, and having an enclosed volume of about $150 \mathrm{ml}$. The cover was a ground glass fit. One 5-ml beaker containing $3 \mathrm{ml}$ of a solution of titanium ions in 9 molar sulfuric acid and a second 5 -ml beaker containing $3 \mathrm{ml}$ of 9 molar sulfuric acid, as a control solution, were placed in the weighing bottle with the paper carton stock. About $15 \mathrm{ml}$ of distilled water was poured on the paper and the weighing bottle was closed and allowed to stand for 6 to $24 \mathrm{hr}$ at $26^{\circ} \mathrm{C}$. The evolved gases were absorbed by the titanium-sulfuric acid solution and the sulfuric acid solution forming a yellow layer at the surface of each solution. The solutions were stirred and then viewed from the top of the beakers to determine the difference in the depth of the yellow color. The aqueous solution in contact with the paper was also tested for peroxide by adding 
$1 \mathrm{ml}$ of that solution to $3 \mathrm{ml}$ of the titanium-sulfuric acid solution and to $3 \mathrm{ml}$ of the sulfuric acid solution in 5 -ml beakers.

The titanium solution was prepared by treating about $10 \mathrm{~g}$ of titanium dioxide with about $150 \mathrm{ml}$ of concentrated sulfuric acid in a glass stoppered bottle at $50{ }^{\circ} \mathrm{C}$ for one week with occasional stirring and filtering through a medium porosity glass filter without pressure. Filtration may require 1 to 3 days and the funnel should be kept covered. The filtrate was diluted with an equal volume of distilled water by slowly pouring the sulfuric acid solution down the side of the flask into the distilled water with frequent mixing to obtain a 9 molar solution containing titanium ions. A 9 molar solution of sulfuric acid was made up for the control solution.

The test for peroxide formation was positive in the evolved gases and the aqueous solutions for the three cartons. The yellow color in the test solution was light for cartons aged for 7 days at $100{ }^{\circ} \mathrm{C}$, more yellow after aging 14 days at $100{ }^{\circ} \mathrm{C}$, and a deep yellow after aging $2 \mathrm{hr}$ at $175^{\circ} \mathrm{C}$. Cartons aged at $100^{\circ}$ for 7 and 14 days showed some visual degradation. Cartons aged at $175{ }^{\circ} \mathrm{C}$ for $2 \mathrm{hr}$ became brittle and sometimes slightly charred showing exteme degradation. One high grade filter paper, aged at $175^{\circ}$ for $2 \mathrm{hr}$, gave a positive test for peroxides in the gases evolved. A sample of multigraph paper, brownish in color and about 20 years old, also evolved peroxide gases. One cellulose acetate microfilm base, with gelatin layer removed, aged at $175{ }^{\circ} \mathrm{C}$ for $2 \mathrm{hr}$ gave a negative test for peroxides in the gases evolved and in the aqueous solution.

The paper cartons underwent degradation during aging, probably forming peroxide groups in the cellulose as indicated by Kleinert and Marraccini [3]. Resinous materials, usually present, may also form peroxides. These results lend considerable weight to the theory that paper cartons slowly degrade with time especially at high temperatures and high relative humidities to form peroxides which attack the image silver in the microfilm to form blemishes. Peroxide groups probably form in the paper carton over a period of time and are released as a gas by hydrolysis at high relative humidity. This reaction may be repeated several times as spots with several rings have been found on microfilm in storage. Spots with many rings were produced in the laboratory by exposing the microfilm several times to $1 \mathrm{~cm}^{2}$ of the peroxide paper containing about $80 \mu \mathrm{g}$ of hydrogen peroxide. Thus Liesegang reactions may not be required to account for the ring structure, as has been suggested.

\section{Absorption of Peroxide by the Cellulose Acetate Base}

Four microfilm bases or supports, made by four manufacturers, were permeable to gaseous hydrogen peroxide. Microfilm base samples, clear or dyed, used for tests were prepared by removing the gelatin layer and backing, if any, from unprocessed microfilm by scraping with a razor blade. Processed microfilm susceptible to blemish formation was stapled to the microfilm base samples with the emulsion side next to the microfilm base and the other side of the microfilm base was sealed with petroleum jelly to the top of a glass vial, $15 \mathrm{~mm}$ in diameter and $45 \mathrm{~mm}$ long, containing peroxide paper having about $40 \mu \mathrm{g}$ of hydrogen peroxide per $\mathrm{cm}^{2}$. The vial was then stored in a desiccator jar at 86 percent relative humidity at $26{ }^{\circ} \mathrm{C}$ for $24 \mathrm{hr}$. The hydrogen peroxide diffused through each of the four microfilm bases, forming a few light yellow spots and light even yellowing in the image silver of the attached processed microfilm. Processed microfilm susceptible to blemish formation sealed to the vial in the above test with the base exposed to the gas suffered the same blemish formation in the image silver by diffusion of the peroxide through the microfilm base.

The four above microfilm bases were tested for absorbed hydrogen peroxide. Samples were stapled between two sheets of peroxide paper containing about $170 \mu \mathrm{g}$ of hydrogen peroxide per $\mathrm{cm}^{2}$, stored in a glass bottle at room humidity and $26{ }^{\circ} \mathrm{C}$ for $24 \mathrm{hr}$, removed from the bottle, exposed to room atmosphere for 24 $\mathrm{hr}$, and tested for peroxide by dissolving a $1 \mathrm{~cm}^{2}$ sample in $3 \mathrm{ml}$ of the titanium-sulfuric acid solution described in section 6 . When the sample contained absorbed peroxide it turned yellow before complete solution and dissolved in about $2 \mathrm{hr}$ with occasional stirring to form a yellow colloidal solution. If no peroxide was present the sample turned white before complete solution and the colloidal solution was white. The microfilm bases formed a yellow color in the titanium-sulfuric acid solution while dissolving and in the colloidal solution. An uncoated cellulose acetate strip also showed a yellow color in the titanium-sulfuric acid solution.

Microfilm base which absorbed and retained the peroxide was used to detect peroxide evolved by aged storage cartons. Two of the microfilm bases did not retain the absorbed peroxide during the tests on the aged storage cartons. It is not known what determines the retention of peroxide by film bases. The subbing, plasticizer or other compounds may be determining factors. Samples of clear microfilm base were stored at 86 or 100 percent relative humidity and $26{ }^{\circ} \mathrm{C}$ in a desiccator jar for $24 \mathrm{hr}$ in closed microfilm storage cartons which had been aged for 14 days at $100{ }^{\circ} \mathrm{C}$ or $2 \mathrm{hr}$ at $175{ }^{\circ} \mathrm{C}$. The microfilm base was tested for absorbed peroxide immediately after removal from the carton by dissolving $1 \mathrm{~cm}^{2}$ samples in $3 \mathrm{ml}$ portions of each of the titanium-sulfuric acid solution and the sulfuric acid solution described in section 6. Gaseous compounds other than peroxide formed a yellow colloidal solution in both of the above solutions. The samples turned yellow in both solutions before dissolving but the one in the titanium-sulfuric acid solution was always a deeper yellow than the control solution. The color in the colloidal solution containing titanium ions was also always a deeper yellow than the control solution and this was taken as evidence that peroxide had been emitted by the aged cartons and absorbed by the microfilm base. 
Absorption of peroxides by the microfilm was shown to precede blemish formation. Samples of a microfilm susceptible to blemish formation were exposed $4 \mathrm{hr}$ to $1 \mathrm{~cm}^{2}$ of peroxide paper, containing about $80 \mu \mathrm{g}$ of hydrogen peroxide, in a desiccator at 86 percent relative humidity and $26{ }^{\circ} \mathrm{C}$. The samples evidenced no blemishes when examined with a stereomicroscope at a magnification of 30 . The samples were immediately stored in another desiccator containing no peroxide at 86 percent relative humidity and $26^{\circ} \mathrm{C}$. After $20 \mathrm{hr}$ a few colorless minute spots formed in the high densities of the image silver, indicating that peroxide had been absorbed before spots developed.

\section{Summary}

Peroxide paper or zinc powder were used as peroxide sources for testing the susceptibility of processed microfilm to blemish formation. Microfilm samples having a high susceptibility to spot formation were used as controls in the test procedures.

Conditioning of processed microfilm at 86 percent relative humidity and $26{ }^{\circ} \mathrm{C}$ reduced blemish formation. Only a few spots formed in the high densities after conditioning for 7 months. About 10 percent as many spots formed after conditioning for 41 days, about 50 percent as many spots after 14 days and a slight reduction in spot formation after 7 days when compared to spot formation in the control samples. Samples desiccated for 5 months over anhydrous calcium sulfate showed a noticeable decrease in spot formation but after storage for about 6 months at room atmosphere, the spot formation was similar to that of the control samples.

Coarse-grain microfilm fixed in a neutral bath or an acid hardening bath and washed 3 to $30 \mathrm{~min}$ in chlorinefree tap water formed no spots but a light even yellowing of the image silver when exposed to peroxide. In comparison, fine-grain microfilm was very susceptible to spot formation when processed by the same procedures. The coarse-grain microfilm fixed in a nonhardening or acid-hardening bath and washed in tap water containing $1.2 \mathrm{ppm}$ of chlorine showed a light even yellowing in samples washed 3 and $7 \frac{1}{2} \mathrm{~min}$ and a few spots in those washed 15 to $60 \mathrm{~min}$. In comparison, fine-grain microfilm formed many spots if washed $3 \mathrm{~min}$ but none in those washed 15,30 , and $60 \mathrm{~min}$ when processed by the same procedures.
Fine-grain microfilm fixed in an ammonium thiosulfate nonhardening bath and washed in chlorine-free tap water showed more resistance to spot formation than film fixed in a sodium thiosulfate nonhardening bath. Fing-grain microfilm fixed in the ammonium thiosulfate acid hardening bath and washed in chlorinefree tap water formed a few small spots and a trace of even yellowing on samples washed $3 \mathrm{~min}$ and no spots on samples washed 15 or $30 \mathrm{~min}$. In comparison, fine-grain microfilm fixed in the sodium thiosulfate acid hardening bath by the same procedure was very susceptible to spot formation. Fine-grain microfilm fixed in an ammonium thiosulfate acid hardening bath and washed in running tap water containing $1.2 \mathrm{ppm}$ of residual chlorine formed blemishes about as readily as film fixed in a sodium thiosulfate acid hardening bath by the same procedure.

Paper cartons used for storage of microfilms aged for 7 and 14 days at $100^{\circ} \mathrm{C}$ and for $2 \mathrm{hr}$ at $175^{\circ} \mathrm{C}$ gave a positive test for peroxide in both the gases evolved and the water solution in contact with the sample tested.

Microfilm base readily absorbed hydrogen peroxide when clamped between sheets of the peroxide paper. Microfilm base samples stored in aged paper cartons at 86 or 100 percent relative humidity and $26^{\circ} \mathrm{C}$ gave a positive test for peroxide, evidencing absorption of peroxide emitted by the storage carton. Tests indicated that hydrogen peroxide diffused through the base of microfilm to form small spots and even yellowing in the image silver. Spots developed in microfilm when the exposure to peroxide was terminated before spot formation was visible.

\section{References}

[1] Pope, C. I., Blemish formation in processed microfilm, Nat. Bur. Stand. (U.S.), 72A (Phys. and Chem.), No. 3, 251-259 (MayJune 1968).

[2] Henn, R. W., and D. G., Wiest, Microscopic spots in processed microfilm; their nature and prevention, Photo. Sci. Eng. 7, 253 (1963).

[3] Kleinert, T. N., and Marraccini, L. M., Aging and colour reversion of bleached pulps, Svensk Papperstidning 66, 189-195 (Jan.-June 1963). 